\title{
AS APRENDIZAGENS DA GINÁSTICA NO ENSINO FUNDAMENTAL: A ORGANIZAÇÃO DOS DADOS DA REALIDADE
}

\author{
GYMNASTICS IN ELEMENTARY EDUCATION: ORGANIZATION OF DATA ON \\ REALITY
}

LOS APRENDIZAJES DE LA GIMNASIA EN LA EDUCACIÓN PRIMARIA: ORGANIZACIÓN DE LOS DATOS DE LA REALIDAD

\begin{abstract}
Ana Rita Lorenzini*, Celi Nelza Zülke Taffarel**, Lívia Tenório Brasileiro*, Marcelo Soares Tavares de Melo*, Marcílio Barbosa Mendonça de Souza Júnior*, Rodrigo Oliveira Falcão*
\end{abstract}

\begin{abstract}
Palavras chave
Ensino.

Aprendizagem.

Ginástica.

Resumo: $O$ objetivo consistiu em analisar as aprendizagens da ginástica que entrelaçam o conteúdo e o signo em aulas de Educação Física na perspectiva crítico-superadora, no primeiro ciclo do ensino fundamental. Alinhada à abordagem teórica marxista, a pesquisa utilizou o método da ascensão do abstrato ao concreto, do geral ao singular, analisando 28 aulas documentadas num diário de campo. Concluiu-se que o processo de identificação dos dados da realidade materializou as aprendizagens elevando os níveis do pensamento teórico nos aprendizes que formaram representações sobre a ginástica, sendo esta um conteúdo e signo da Educação Física.
\end{abstract}

Keywords:

Teaching.

Learning.

Gymnastics.

Palabras clave:

Enseñanza.

Aprendizaje.

Gimnasia.

Abstract: The purpose of this study was to analyze gymnastics learning interconnecting content and sign in Physical Education classes based on the "Critical-Overcoming" perspective in the 1st cycle of basic education. Aligned to the Marxist theoretical approach, the study used the method of ascending from abstract to concrete, from general to unique, in order to analyze 28 classes documented in a field diary. It found that the process of identifying data on reality materialized learning, raising theoretical thinking levels in learners that formed representations about gymnastics, which is a content and a symbol of Physical Education.

Resumen: Resumen: El objetivo fue analizar los aprendizajes de gimnasia que entrelazan contenido y signo en las clases de Educación Física desde la perspectiva crítico-superadora, en la enseñanza básica. En línea con el enfoque teórico marxista, la investigación utilizó el método de ascenso de lo abstracto a lo concreto, de lo general a lo singular, analizando 28 clases documentadas en un diario de campo. Se concluyó que el proceso de identificación de los datos de la realidad materializó los aprendizajes, elevando los niveles del pensamiento teórico en los aprendices, que formaron representaciones sobre la gimnasia, que constituye un contenido y signo de la Educación Física.
**Universidade de Pernambuco (UPE). Recife, PE. Brasil.

E-mail: e-mail: arita@globo.com

**Universidade Federal da Bahia (UFBA). Salvador, BA, Brasil. E-mail: taffarel@ufba.br

Recebido em: 25-05-2014 Aprovado em: 11-06-2015 (c) (1) (8) Licence 


\section{INTRODUÇÃO}

Nossa pesquisa se insere entre aquelas que tratam da prática pedagógica e da luta travada pela mudança de seus rumos, especialmente no campo da Educação Física (EF). Especificamente, o tema investigado é a ginástica na Educação Física Escolar (EFE), no primeiro ciclo de aprendizagem. Nisto o objeto de estudo são as aprendizagens da ginástica, na perspectiva crítico-superadora da Educação Física.

Lisboa e Teixeira (2012) investigaram a ginástica fazendo um balanço sobre a atualidade da produção científica no Brasil até 2011, destacando a produção sobre a ginástica na Educação Física Escolar nos periódicos nacionais (Motrivivência, Movimento, Revista do Colégio Brasileiro de Ciências do Esporte - RBCE, Motriz e Pensar a Prática) e no banco de teses da Coordenação de Aperfeiçoamento de Pessoal de Nível Superior (Capes). Os autores identificaram nas revistas 51 artigos que trataram das problemáticas da ginástica, localizando 11 produções sobre a ginástica escolar. Já na Capes foram consultadas 166 teses e dissertações disponíveis, no período de 1987 a 2010, sendo 152 de mestrado e 14 de doutorado, identificando nove trabalhos referentes à ginástica na EFE, sendo três teses e seis dissertações. Mediante os referidos resultados evidenciou-se que a produção sobre ginástica ainda é reduzida na EFE, fato que justifica novas investigações na área.

Para Lorenzini (2013), a ginástica em sua especificidade necessita ser tratada historicamente para que 0 estudante da educação básica se aproprie de suas bases e fundamentos, das modalidades e materiais, das consequências da exercitação para as funções vitais, das capacidades e habilidades contidas no referido conhecimento, dentre outros, apropriando-se do conhecimento.

A ginástica é um conteúdo de ensino-aprendizagem da Educação Física enquanto componente curricular da escola, trabalhada nos diferentes ciclos da educação básica, visando contribuir com a reflexão e intervenção dos aprendizes, na área da Cultura Corporal, na perspectiva do conhecimento crítico e superador, sendo retraçada desde sua gênese, numa visão de historicidade onde o sujeito reflete sobre a ação gímnica, a exercitação do tipo corporal, com significados sociais e sentido pessoal (LORENZINI, 2013, p.231).

Para Lorenzini (2013), a ginástica também é um signo da EFE quando forma as estruturas que potencializam a elevação dos níveis do pensamento no estudante por meio das capacidades psíquicas superiores. O signo está nas aprendizagens escolares que geram a formação de definições e conceitos (MARTINS, 2011).

Ao explicar o signo, Vygotsky $(1984,1989)$, afirma que promove a mediação, na qual uma coisa se encontra interposta entre um ponto e outro com o intuito de relação. É um instrumento especial, uma ferramenta que se situa na pessoa e medeia a relação e a atitude do sujeito com outros e consigo mesmo localizando-se entre o sujeito e a atividade, mediando a influência do sujeito sobre o objeto.

Para Soares et al. (2012) ${ }^{1}$, na Educação Física orientada pela Cultura Corporal, a metodologia crítico-superadora (MCS) incorporou o princípio vygotskyano da interação social, que possibilita a reflexão pedagógica que potencializa definições e conceitos referentes

1 A primeira versão desta obra é de 1992, a qual está registrada conforme Dados Internacionais de Catalogação na Publicação (Câmara Brasileira do Livro, SP, Brasil) como Metodologia do ensino de educação física / coletivo de autores. São Paulo: Cortez, 1992. (Coleção magistério $2^{\circ}$ grau. Série formação do professor). 
às ações corporais, às emoções, à elaboração do pensamento no estudante, gerando o desenvolvimento cultural do sujeito histórico que contribui com a transformação social, na construção da racionalidade histórica. Também contribuiu com a aprendizagem de conteúdos específicos (o Jogo, a Dança, a Ginástica, o Esporte, a Luta, dentre outros).

Na referida perspectiva, a EFE é relevante quando visa à aprendizagem do estudante no processo de apropriação e produção dos saberes corporais cujo objetivo maior é 0 desenvolvimento humano. Na escola, é a disciplina de conteúdo com fim formativo que promove a apreensão do conhecimento histórico indispensável ao desenvolvimento do pensamento sobre a Cultura Corporal, expressando o caráter político do ato educativo.

Ainda para justificar a investigação recorremos à base teórica subjacente aos ciclos de aprendizagem e à formação do pensamento teórico nos estudantes, priorizando os argumentos da metodologia crítico-superadora (MCS) e da Psicologia Histórico-Cultural (PHC), visto que, para a organização curricular do conhecimento em ciclos, a MCS elencou subsídios da PHC 2 referenciada em Vygotsky e sucessores ${ }^{3}$.

Frente aos elementos e argumentos supracitados nossa indagação vem a ser: quais são as aprendizagens da ginástica que entrelaçam o conteúdo ao signo no primeiro ciclo do ensino fundamental tratadas na Educação Física Escolar na perspectiva crítico-superadora? Nosso objetivo consistiu em analisar as aprendizagens da ginástica que entrelaçam o conteúdo e o signo em aulas de Educação Física na perspectiva crítico-superadora, no primeiro ciclo do ensino fundamental.

Esperamos assim, de um modo geral, contribuir com o debate acerca da Educação Física Escolar a partir das aprendizagens da ginástica com implicações na prática pedagógica.

\section{BASES TEÓRICAS}

Passamos a elencar a base conceitual fundamental a esta investigação mediante argumentos de Leontiev (1978), Vygotsky (1984, 1989), Martins (2011), Soares et al. (2012) e Lorenzini (2013), finalizando com o estabelecimento de nexos e relações com as aprendizagens da ginástica, por ser esta um dos conteúdos da Educação Física Escolar.

Para Leontiev (1978), o desenvolvimento do psiquismo apareceu com a sociedade humana, com os fenômenos externos da cultura material e intelectual, com o trabalho. Assim emerge o desenvolvimento do pensamento lógico ou da aquisição do saber (conceitos) que ocorre por um processo de apropriação da cultura criada pelas gerações precedentes, passando às gerações seguintes, que multiplicam e aperfeiçoam o conhecimento pelo trabalho e pela luta para a aquisição das riquezas culturais que lhes foram transmitidas, desenvolvendo a humanidade.

Por sua vez, Vygotsky (1984) contribuiu com a ideia de que o conhecimento necessita ser trabalhado em diferentes níveis do desenvolvimento do pensamento, buscando vínculos

\footnotetext{
2 A Psicologia Histórico-Cultural estuda o psiquismo humano e representa esforços em prol da formulação e consolidação da Psicologia científica fundamentada na concepção filosófica do materialismo histórico dialético, com os princípios metodológicos que Ihe conferem sustentação, aliado aos ideais de superação do sistema político-econômico capitalista (MARTINS, 2011).

3 Luria e Vygotsky (1992) preocuparam-se com desenvolvimento humano, e a preocupação em evitar uma visão essencialista e a-histórica da natureza humana levou ao interesse pelo desenvolvimento histórico da psique humana valorizando o lado prático, produtivo da sociedade que necessitou criar ferramentas para o trabalho humano desenvolvendo a psique do homem. A objetividade do conhecimento está situada no social e nas atividades produtivas do homem na história.
} 
entre 0 nível real e o potencial. Para 0 autor, o ensino promove a superação do nível de desenvolvimento real, na direção da formação de conceitos em diferentes níveis, num processo em construção. $O$ desenvolvimento potencial faz surgir algo novo, nos domínios dos processos funcionais superiores, indispensáveis à formação dos sujeitos históricos.

Cabe à escola o desenvolvimento cultural das funções psíquicas superiores que, para Vygotsky (1989), são: a percepção do objeto, a atenção voluntária, a memória intervinda, a imaginação. Para o seu desenvolvimento faz-se necessário o processo de internalização das aprendizagens gerando definições e conceitos produzidos na condição explicitada a seguir.

No desenvolvimento cultural, todas as funções entram duas vezes em cena, em dois planos diferentes: primeiro, no social, logo no plano psicológico: primeiro como uma forma de cooperação entre as pessoas, como uma categoria coletiva e interpsicológica, depois como meio de comportamento individual, como uma categoria intrapsicológica (VYGOTSKY, 1989, p. 223).

Compreendemos que as aprendizagens que geram o desenvolvimento de signos iniciam com um processo externo, coletivo, social, interativo, prosseguindo para a internalização no plano mental de cada sujeito ao operar os signos.

O legado vygotskyano contribuiu com o desenvolvimento do psiquismo humano 4 a partir de determinantes localizados na cultura historicamente sistematizada pelo trabalho humano, investigando a formação das funções psíquicas superiores. Estas ainda não estão plenamente conceituadas nos dias atuais, mas no legado vygotskyano, segundo Martins (2011), são formações culturais, implicam o domínio do homem sobre a natureza e sobre si mesmo e sustentam atividades complexas culturalmente desenvolvidas.

Vygotsky (1984) explicou o pensamento humano mediante as interações sociais que possibilitam transformar a natureza e ser transformado por ela, tendo no organismo e no meio as influências recíprocas e complementares do biológico e do social, no desenvolvimento. Para o autor, a internalização das atividades socialmente enraizadas e historicamente desenvolvidas constitui 0 aspecto característico da psicologia humana. A internalização é a reconstrução interna de uma operação externa, ou seja, é o processo que transmuta formações externas em internas.

Vygotsky (1984) formulou a ideia de que a aprendizagem conduz ao desenvolvimento, introduzindo a categoria denominada zona de desenvolvimento proximal (ZDP) ${ }^{5}$. 0 significado desta categoria afirma que, de acordo com o nível do estudante quando alcança certa meta, em cooperação com adultos ou com colegas mais experientes, pode-se prever seu desempenho posterior, independente, paraalcançar uma nova meta. Neste rumo, emerge a formação de definições e conceitos que, para o referido autor e seus colaboradores (DAVYDOV, 1982, LEONTIEV, 1978, LURIA, 1992), inicia com o pensamento sincrético e chega ao pensamento sintético.

Compreendemos que o estágio do pensamento sincrético é o da experiência sensível, das impressões desordenadas, no qual o aprendiz percebe os dados da realidade que, nesta investigação, reportam-se à ginástica, de forma difusa, misturada, pouco relacionada entre si,

40 psiquismo é a unidade material e ideal que se desenvolve socialmente. É o conjunto das relações sociais transportadas ao interior e convertidas nos fundamentos da estrutura social da personalidade (MARTINS, 2011).

5 A ZPD define a distância entre o nível de desenvolvimento real, determinado pela capacidade de resolver um problema sem ajuda, e o nível de desenvolvimento potencial, determinado através de resolução de um problema sob a orientação de um adulto ou em colaboração com outro companheiro. Define as funções que ainda não amadureceram mas que estão em processo de maturação, num estado embrionário. Nisto, 0 ensino deve tratar as funções que se encontram em fase de desenvolvimento na ZDP (VYGOTSKY, 1984). 
com nexos vagos, subjetivos, orientados pela percepção aparente, por imagens. Já a síntese é uma nova produção oriunda da elaboração do pensamento sobre o conhecimento que, para Shardakov (1978), permite um novo conhecimento da realidade, por isso não pode ser reduzida à união mecânica de partes para formar um todo, nem à simples soma dos elementos de um conjunto porque requer o estabelecimento de relações entre as partes e o todo.

Subsidiados nos estudos dos autores supramencionados, Varjal ${ }^{6}$ e Soares et al. (2012) trataram os ciclos de aprendizagem, na área da Educação Física Escolar, como um processo de organização do pensamento sobre o conhecimento, no qual o estudante é o sujeito que interpreta e compreende o conhecimento, e nisto o conteúdo vai sendo constatado e explicado, num processo de aproximação do real. Esse referencial está baseado na concepção de currículo organizado em ciclos, o qual visa superar a seriação ${ }^{7}$. Ele propõe que as referências do pensamento no estudante vão sendo ampliadas, de forma espiralada, com a constatação dos dados da realidade, a interpretação, a compreensão e a explicação do conhecimento.

Soares et al. (2012) optaram por uma ótica de processos de conhecimentos, e nestes um estudante pode lidar com diferentes ciclos ao mesmo tempo, mas o ciclo tem uma configuração própria que define os níveis de elaboração do pensamento sobre o conteúdo. 0 primeiro ciclo trata da "Organização da identidade dos dados da realidade".

Para Lorenzini (2013), esse é o estágio do pensamento sincrético, da experiência sensível, das impressões desordenadas, no qual o aprendiz percebe os dados da ginástica de forma difusa, misturada, pouco relacionada entre si, com nexos vagos, subjetivos, orientados pela percepção aparente, por imagens. $O$ estudante deve ser orientado a formar representações no seu pensamento (definições que antecedem os conceitos), ao categorizar os objetos, classificá-los e associá-los por suas semelhanças e diferenças visíveis e sentidas. Esse ciclo é a base para a formação das generalizações correspondentes ao segundo e terceiro ciclos do ensino fundamental (hoje $4^{\circ}$ ao $9^{\circ}$ anos).

Em seus aspectos gerais, a referida discussão vem sendo ampliada na Psicologia Histórico-Cultural, a exemplo da investigação de Martins (2011). A autora afirma que é preciso reconhecer quais são as funções psíquicas superiores e estudar o seu desenvolvimento no processo de formação do indivíduo como um ser essencialmente cultural, sabendo que 0 desenvolvimento do pensamento teórico corresponde à apropriação dos signos da cultura. Para a autora, "o substrato de toda formação superior é a inferior, que se encontra nela negada e conservada, isto é, transformada pelo contínuo confronto entre as suas expressões culturais e naturais, respectivamente" (MARTINS, 2011, p. 72). Assim, compreendemos que o velho, a exemplo das representações da ginástica, não desaparece quando nasce o novo, mas é superado por ele e, sendo negado pelo novo, se transporta a ele e existe nele.

Martins (2011) analisou o papel da educação escolar no desenvolvimento psíquico, discutindo e relacionando a concepção de homem e de conhecimento, de aprendizagem e ensino em suas relações psíquicas. Para a autora, o homem como ser social tem o próprio

6 VARJAL, E. Subsídios para o trabalho pedagógico no ciclo de organização da identificação dos dados da realidade. Recife, 1990. mimeo.

7 Na seriação, o conhecimento foi partido, ficando contido nas disciplinas, distribuído em anos e subdividido em unidades para controle da velocidade de aprendizagem. Foi determinada uma quantidade mínima de conhecimento a ser dominada pelos alunos. Os conhecimentos devem ser verificados em processos pontuais de avaliação. Assim, quem domina avança e quem não aprende repete o ano, ou sai da escola existindo também a lógica da troca da aprendizagem pelas notas. A escola distancia-se das suas relações com a vida, com a prática social. Surgiu das necessidades da formação da sociedade capitalista, ou seja, suas forças produtivas necessitavam de uma "escola que preparasse rapidamente, e em série, recursos humanos para alimentar a produção de forma hierarquizada e fragmentada” (FREITAS, 2003, p. 27). 
desenvolvimento condicionado pelo trabalho que o vincula à natureza, mas é a sua prática, a produção, a conquista que o caracteriza como ser humano humanizado, ou seja, a legitimidade na educação escolar requer a necessidade fundamental de apropriação do patrimônio cultural da humanidade, cuja função consiste em

[...] promover a socialização dos conhecimentos universais, representativos das máximas conquistas científicas e culturais da humanidade, na ausência das quais a captação das leis que regem o desenvolvimento histórico de todos os fenômenos se torna impossível (MARTINS, 2011, p. 215).

Ao relacionar as interdependências entre o ensino e o desenvolvimento dos processos funcionais, Martins (2011) confirmou que o desenvolvimento do psiquismo humano identificase com a formação das funções psíquicas superiores e que, na educação escolar, a referida formação é atribuída ao ensino sistematicamente orientado à transmissão dos conceitos não cotidianos, científicos, logo não são quaisquer ações e conteúdos que desenvolvem as referidas funções.

Compreendemos que as argumentações dos autores supracitados estão subjacentes às aprendizagens de todo conteúdo trabalhado na prática pedagógica em geral, incluindo as particularidades da Educação Física, dos ciclos de aprendizagem e da ginástica. Nesta última,

[...] o problema fundamental colocado ao sujeito da ação gímnica consiste em desafiar as próprias possibilidades de exercitação visando o pensamento teórico. Neste rumo, a ginástica torna-se um signo que está no sujeito e faz a mediação entre o mesmo e o objeto de estudo, produzindo a formação das representações iniciais passando para as generalizações. (LORENZINI, 2013, p. 109).

Com os argumentos explicitados na base teórica desta investigação identificamos que a ginástica tem potencial para ser um dos conteúdos e signo da Educação Física Escolar, e isso possibilita o estabelecimento de nexos e relações com o referencial aqui apresentado.

\section{DECISÕES METODOLÓGICAS}

A investigação está alinhada à abordagem teórica marxista, enfatizando o fenômeno material com suas múltiplas determinações, descrevendo as aprendizagens do $1^{0}$ ciclo, revelando sentidos e significados, princípios e categorias subjacentes. A fundamentação teórica foi baseada na literatura especializada referente ao objeto de estudo e suas explicações.

Já o instrumento utilizado para coleta dos dados empíricos foi um diário de campo, oriundo das experiências realizadas no processo de formação continuada dos professores de EF de uma rede estadual de ensino, produzido por duas professoras concursadas para a referida disciplina que trabalhavam na escola investigada.

$\mathrm{Na}$ escola foi selecionada uma só turma de estudantes do $1^{0}$ ciclo de aprendizagem, que foi investigada quando estava na $1^{\underline{a}}$ unidade do $2^{\circ}$ e do $3^{\circ}$ anos do ensino fundamental, ou seja, na referida turma foram regidas aulas de EF em duas unidades de ensino-aprendizagem da ginástica, trabalhadas em dois anos consecutivos sempre na 1a unidade de ensino da instituição, que seguia as orientações teóricas e metodológicas do currículo do seu Estado.

As aulas foram planificadas, operacionalizadas, avaliadas, filmadas e transcritas pelas professoras de EF, atendendo inclusive aos princípios éticos para pesquisa ao solicitar a permissão para a escola e para os responsáveis pelas crianças visando coletar dados, 
explicitando os confortos, desconfortos e benefícios, inclusive para as crianças, cumprindo a resolução de ética e pesquisa com seres humanos de nำ466/2012.

A investigação se apoiou em fontes de natureza bibliográfica e documental para responder à pergunta-síntese; instrumentos e técnicas de coleta e tratamentos de dados; organização e sistematização de resultados chegando à análise do material e argumentações. (SÁNCHEZ GOMBOA, 2008).

A fonte empírica foi o diário de campo, com 61 laudas digitadas em espaço simples. 0 referido instrumento constituiu-se com o registro e descrição dos dados sobre a sistematização da ginástica em aulas de Educação Física, contendo: o plano de ensino, a delimitação do objetivo geral e dos específicos, do conteúdo, da metodologia de ensino utilizada em aulas, da avaliação das aprendizagens dos estudantes, dentre outros. Foram registrados 28 planos de aula (aula, oficina, seminário, festival) ${ }^{8}$ ministrados a uma única turma com 23 estudantes, a qual foi incluída porque estava finalizando o $1^{\circ}$ ciclo de aprendizagens e por ter aulas de EF com uma das professoras da escola há mais de um ano.

Para analisar o material coletado utilizou-se o método da ascensão do abstrato ao concreto, do geral ao singular, em movimento constante. O método pôde ser compreendido com as investigações de Davydov (1982) referentes ao conhecimento da abordagem dialética na formação de conceitos, enfatizando o princípio da atividade adequada que transforma o objeto e o sujeito da aprendizagem mediante a ascensão dos fenômenos percebidos como concretos para a abstração substancial, expressando a contradição interior e original do objeto investigado. A abstração prossegue para a generalização concreta, deduzindo as várias manifestações particulares de sua base de desenvolvimento. Logo, os verdadeiros conceitos teóricos explicam as qualidades internas dos objetos e orientam a atividade prática.

No movimento da realidade, como é o caso da ginástica em nossa investigação, para Cheptulin (2011), o que exprime a semelhança do fenômeno investigado é o geral e o que distingue os objetos ou as manifestações confrontadas constitui o particular. 0 singular é a propriedade que não se repete na formação material, pois é a formação em si, e o particular é o singular e o geral numa totalidade.

Para Cheptulin (2011), as propriedades e as ligações que se repetem nos objetos e seus processos constituem o geral. Cada objeto representa a unidade do singular e do geral, do que não se repete e do que se repete. $O$ singular e o geral se manifestam no particular. A correlação entre o singular e o geral no particular manifesta-se igualmente na transformação do singular em geral, e vice-versa, no processo do movimento e do desenvolvimento das formações materiais.

Para Kosik (2011), o método da ascensão requer: a apropriação da matéria mediante o domínio do material; análise de cada forma de desenvolvimento do material; a investigação da coerência interna. Nesta lógica, passamos a tratar os dados empíricos, os resultados e a discussão da investigação.

\section{ANÁLISE E DISCUSSÃO}

Neste tópico nos reportamos à ginástica no ciclo da organização dos dados da realidade. Conforme o diário de campo, o objetivo geral elencado do plano de ensino do professor 
consistiu na ação dos estudantes visando identificar os conhecimentos/conteúdos: Ginástica, Jogo, Dança, Luta, Esporte, contextualizando-os, relacionando-os ao cotidiano, refletindo sobre definições, atitudes, procedimentos e as ações colocadas em prática (habilidades), reorganizando o conhecimento tratado em aulas, oficinas, seminários e festivais, priorizando a constatação dos dados da realidade com formação de representações em cada tema da Cultura Corporal, extrapolando conhecimento para a comunidade escolar.

Observamos que o referido objetivo traduz fundamentos que orientam a materialização das referências da Cultura Corporal (SOARES et al., 2012) incorporadas nos ciclos de aprendizagem, desenvolvendo experiências curriculares que enfrentem as contradições da negação do conhecimento e do rebaixamento das capacidades ontológicas do ser humano.

A partir do objetivo geral do ciclo foram delimitados o objetivo geral e os específicos para o trato da ginástica numa única turma, trabalhada em duas unidades temáticas e em dois anos consecutivos, totalizando 28 aulas constitutivas do currículo da escola. Esquematizamos no Quadro1 os resultados quantitativos no conjunto de aulas de EF tratando da ginástica, no formato de: aula, oficina, festival e seminário.

Quadro 1 - Demonstrativo do registro de 28 aulas

\begin{tabular}{|c|c|c|c|c|c|}
\hline TEMPO & HORA-AULA & OFICINA & FESTIVAL & SEMINÁRIO & TOTAL \\
\hline \multirow{2}{*}{ I CICLO } & $2^{2}$ ano $-11 \mathrm{~h}$ & - & $2 \mathrm{~h} / \mathrm{a}$ & - & $13 \mathrm{~h} / \mathrm{a}$ \\
& $3^{\mathrm{a}}$ ano $-9 \mathrm{~h}$ & $2 \mathrm{~h} / \mathrm{a}$ & $3 \mathrm{~h} / \mathrm{a}$ & $1 \mathrm{~h} / \mathrm{a}$ & $15 \mathrm{~h} / \mathrm{a}$ \\
\hline TOTAL & $20 \mathrm{~h} / \mathrm{a}$ & $2 \mathrm{~h} / \mathrm{a}$ & $5 \mathrm{~h} / \mathrm{a}$ & $1 \mathrm{~h} / \mathrm{a}$ & $28 \mathrm{~h} / \mathrm{a}$ \\
\hline
\end{tabular}

Fonte: Diário de campo do I ciclo.

Ao analisar as oito aulas iniciais com $02^{\circ}$ ano do ensino fundamental, verificamos que a professora de EF da turma deu ênfase aos cuidados necessários à exercitação gímnica, aos cuidados para não machucar o outro, orientando a turma para a identificação do significado dos fundamentos ginásticos. A 9a aula foi realizada no zoológico da cidade, explorando possibilidades de ação gímnica em materiais não existentes na escola. Nesse tempo pedagógico, as aulas possibilitaram aos estudantes explicar o real visível, a aparência das ações gímnicas produzindo definições como: os giros consistem em dar voltas com 0 corpo; os equilíbrios são o não cair; nos saltos é possível ficar um pouco no ar e cair (aterrissar) sem se machucar, dentre outras.

Inferimos que nas aprendizagens supramencionadas os estudantes formularam definições constitutivas das representações da atividade gímnica, próprias do 1 ciclo de aprendizagens na EFE. Nisto foram materializadas as explicações de Vygotsky $(1984,1989)$ referentes ao signo enquanto ferramenta que faz a mediação do sujeito sobre o objeto. Compreendemos que, no $1^{\circ}$ ciclo, por ser de natureza prioritariamente sensorial, o estudante apreende as manifestações externas do objeto estudado, sua pseudoconcreticidade, suas representações (KOSIK, 2011), que são próprias à condição deste ciclo e, ao mesmo tempo, são a contradição necessária para a elaboração do pensamento nos estudantes.

Entre a $10^{\mathfrak{a}}$ e a $13^{\mathfrak{a}}$ aulas ocorreu a reorganização do conteúdo, que foi socializado no I Festival de Ginástica da Escola, avaliando e encerrando a unidade de ensino-aprendizagem. Nos registros da verbalização dos estudantes foram destacados os conteúdos trabalhados e 
socializados no Festival de Ginástica - os saltos, os rolamentos, as estrelas e a vela. Para os estudantes, os rolamentos e as estrelas são giros; a vela é um equilíbrio; a ginástica foi identificada por estudar os saltos, os giros, os equilíbrios, a exercitação.

Mediante o diário de campo verificamos que, no festival, as crianças observaram outras turmas e, ao serem questionadas sobre o conteúdo, citaram: as pirâmides humanas, rolamentos, saltos, pular corda, lançar a bola, ponte, vela, batatinha frita 1, 2, 3, dizendo que é uma brincadeira de equilíbrio com estátua. Também verbalizaram que a exercitação gímnica pode acontecer na rua, na praça, na praia, na academia, em casa, nos brinquedos do zoológico e que a prática da ginástica pode ser feita com os tios, com a avó e o avô, com os pais. Ao serem questionados sobre o conceito de festival, os estudantes explicaram que ele é festa, apresentação de cinema, de ginástica, de dança, de música, e que a apresentação da turma foi de ginástica, mas disseram que festival não é só apresentação, ele também é avaliação porque observaram os colegas fazendo ginástica e o conteúdo aprendido nas aulas.

Observamos que, na $1^{\underline{a}}$ unidade das aprendizagens, $02^{\circ}$ ano concluiu definindo 0 que é um festival e o que é a ginástica, estabelecendo relações da exercitação com o estudo e o tempo para o lazer. 0 conteúdo foi tratado com definições que antecedem conceitos, não isolados, e o sincretismo foi sendo superado com as vivências e as experiências em aula. 0 trabalho tratou os fundamentos expressos nas diferentes possibilidades de ações corporais das crianças, que foram questionadas com o objetivo de identificar semelhanças e diferenças no conteúdo (saltos, giros, equilíbrios, balanceios, trepar).

As representações formuladas pelos estudantes constituem e superam o pensamento sincrético (KOSIK, 2011, MARTINS, 2011, SOARES et al., 2012, LORENZINI, 2013) que capta as circunstâncias, as aparências da realidade, ou seja, são formas de conhecimento que possibilitam encontrar no conteúdo os traços afins, coincidentes, identificando dados sensoriais da realidade, mas que posteriormente servirão de substrato, de base, para iniciar a formação de conceitos.

$\mathrm{Na} 14^{\mathrm{a}}$ aula do ciclo, sendo a $1^{\underline{a}}$ aula da unidade ginástica do $3^{\circ}$ ano, ocorreu o resgate do conteúdo trabalhado no ano anterior. Foram utilizados registros escritos, distribuídos pela professora de EF a cada estudante, para resgatar o conhecimento já tratado, organizando dados da realidade. Em síntese, para os estudantes aprende-se ginástica para brincar, para relaxar no lazer, nos momentos de descanso, brincadeiras, mas, na escola, é lugar de aprender estudando.

Na sequência das aulas, e ao final de 40 minutos de exercitação gímnica contínua, sentindo os diferentes ritmos cardíacos, os estudantes evidenciaram a curiosidade e a apropriação do conhecimento sobre funções vitais, tratadas com jogos ginásticos a exemplo do 'Pular corda', 'Estátua' etc. (são atividades que possibilitam a vivência dos fundamentos técnicos da ginástica). As crianças sentiram as pulsações em diferentes partes do corpo e demonstraram a compreensão numa síntese, relacionando a exercitação ginástica com o funcionamento da respiração e do coração, dizendo que, durante a prática da ginástica, 0 coração trabalha melhor, o coração bombeia o sangue e faz a circulação pelo corpo.

Verificamos que os estudantes relacionaram a ginástica com suas próprias funções vitais, despertando a curiosidade e a possibilidade de trabalho interdisciplinar com outra área do conhecimento escolar (Ciências) e as relações estabelecidas com cuidados referentes à saúde (subjacente ao conteúdo da ginástica). Isso revela múltiplas determinações do objeto (KOSIK, 2011). 
Verificamos que, entre a $17^{\underline{a}}$ e a $27^{\underline{a}}$ aula, os aprendizes identificaram a Ginástica Artística e a Rítmica, bem como investigaram possibilidades de ação gímnica em um parque, finalizando com a reorganização do conteúdo socializado no segundo festival da escola. $\mathrm{Na} 28^{a}$ aula investigada no $1^{\circ}$ ciclo aconteceu o seminário final, na sala de aula do $3^{\circ}$ ano. Consistiu em assistir a uma síntese mediante um vídeo, sobre o conteúdo tratado na unidade, revendo os jogos ginásticos, o estudo das funções vitais, a vivência no parque e a produção da turma socializada no festival. 0 resgate das imagens teve como intenção concretizar objetivos, na síntese final da unidade, materializando as aprendizagens.

Ao analisar o conhecimento identificamos que, no geral, os conteúdos específicos trabalhados em dois anos consecutivos na unidade de ginástica foram: os fundamentos técnicos; jogos e brincadeiras gímnicos; a Ginástica Artística e a Rítmica; as funções vitais. Das atividades práticas surgiram conteúdos que possibilitaram refletir sobre emoções e valores como o respeito, a cooperação e o direito de aprender, criando uma autoimagem positiva diante da exercitação. Os conteúdos foram vivenciados, experimentados, aprendidos em aulas, festivais e seminário.

Inferimos, a partir do referencial de Cheptulin (2011) que, no geral, o processo das aprendizagens foi marcado pela exercitação gímnica pensada, mediante 0 diálogo e a participação corporal e verbal, com a vivência e a experiência referentes às diferentes possibilidades de andar e de saltar, de equilibrar-se e de equilibrar objetos, de girar/rolar, de balançar-se, de trepar, explorando, prioritariamente, o espaço construído, os materiais móveis e fixos existentes na escola.

Reconhecemos que ao final do $1^{\circ}$ ciclo os estudantes identificaram: os principais fundamentos técnicos da ginástica (saltos, giros, equilíbrios, balanceios, o trepar, dentre outros); que na Ginástica Rítmica há aparelhos como arco, fita, bola e, com os aparelhos, são praticados saltos, giros, equilíbrios, balanceios; com a fita, as crianças lembraram que fizeram "cobrinha, espiral, um oito".

Verificamos que, ao exercitar-se na escola, a criança também passa a sentir/conhecer os sinais dos órgãos vitais (coração, pulmão), a posição do corpo em relação ao espaço - em pé, sentado, deitado, agachado, suspenso, a execução de ações corporais - saltos, giros, equilíbrios, dentre outras, relacionando-as às modalidades esportivas que utilizam materiais/ aparelhos móveis, a exemplo da Ginástica Rítmica e aparelhos fixos na Ginástica Artística. Nesse contexto, ficou demonstrada a formação das representações referentes à ginástica nas explicações dos estudantes referentes ao conteúdo.

Subsidiados em (CHEPTULIN, 2011), inferimos que, no 1ํㅗㄷㅇ, o geral da ginástica foi achado nas propriedades e ligações repetidas, que representam a semelhança do objeto e do seu processo, e emergiu dos fundamentos (técnicas gerais, que na exercitação geraram curiosidade, desafios e emoções); das diferentes posições do corpo; da postura necessária à exercitação; das funções vitais com seu ritmo orgânico; dos valores coeducativos, cooperativos, solidários, que emergiram da aprendizagem e da socialização do conteúdo.

Já o particular da ginástica fez a síntese entre 0 singular e o geral, constituindo 0 tripé da especificidade, distinguindo os objetos confrontados, estabelecendo a diferença. Apresentou-se com um tipo de esforço corporal que configura o rendimento necessário à exercitação/expressão gímnica, praticada sem materiais ou com diferentes aparelhos móveis e 
fixos, estabelecendo as diferenças entre as modalidades ginásticas, relacionando-as ao objeto de estudo no geral e em sua singularidade.

O singular da ginástica está na ação gímnica, na qualidade tal qual é, em si mesma, desnuda, ímpar como prática que tem essência própria e que identifica o fenômeno, com seu próprio objeto e seu processo histórico, seu espaço, distinguindo-a das demais práticas corporais. A ação gímnica requer do sujeito toda a sua atenção e concentração visando conhecer e praticar a exercitação em si mesma, desnuda, interagindo consigo mesmo e com outros, no espaço e tempo de reflexão e intervenção pedagógica.

\section{CONCLUSÃO}

Em síntese, para investigar a ginástica no primeiro ciclo de aprendizagem, na perspectiva Crítico-Superadora da Educação Física foi necessária a descrição de uma sequência de vivências e experiências, de aprendizagens que orientaram os estudantes no sentido de dominar a matéria - a ginástica -, gerando o desenvolvimento das capacidades cognoscitivas necessárias à formação de representações alterando a consciência dos aprendizes no ciclo investigado.

A ginástica é um conteúdo e signo da EFE que potencializa a elevação dos níveis do pensamento no estudante do $1^{\circ}$ ciclo de aprendizagens formando representações. Ou seja, a mediação da ginástica entrou nas intervinculações entre as propriedades essenciais da matéria e da consciência.

Acreditamos que a investigação contribuiu para pensarmos sobre a prática pedagógica transformadora das aprendizagens da ginástica na EFE, porém existe a necessidade de investigações na sequência do ensino fundamental e médio. Ou seja, o aprofundamento e a ampliação da discussão podem gerar mais contribuições à prática pedagógica.

\section{REFERÊNCIAS}

CHEPTULIN, Alexandre. A dialética materialista. São Paulo: Alfa-Omega, 2011.

COSTA CARVALHO, Maria Helena. Avaliar com os pés no chão da escola: reconstruindo a prática pedagógica no ensino fundamental. Recife: Universitária da UFPE, 2000.

DAVYDOV, Vasily Vasilovich. Tipos de generalización en la enseñanza. Habana: Ed. Pueblo y Educación, 1982.

FREITAS, Luiz Carlos de. Ciclos, seriação e avaliação: confronto de lógicas. São Paulo: Moderna, 2003.

KOSIK, Karel. Dialética do concreto. Rio de Janeiro: Paz e Terra, 2011.

LEONTIEV, Alexis. O desenvolvimento do psiquismo. São Paulo: Moraes, 1978.

LISBOA, Núbia dos Santos; TEIXEIRA, Davi Romão. A atualidade da produção científica sobre a ginástica escolar no Brasil. In: FESTIVAL DE GINÁSTICA ALEGRIA NA ESCOLA, SEMINÁRIO INTERATIVO CULTURA CORPORAL, 2., Salvador, 2012. Anais... 1 CD-ROM. 
LORENZINI, Ana Rita. Conteúdo e método da educação física escolar: contribuições da pedagogia histórico-crítica e da metodologia crítico-superadora no trato com a ginástica. 2013. Tese (Doutorado em Educação) - Faculdade de Educação, Universidade Federal da Bahia, Salvador, 2013.

LURIA, Alexander R.; VYGOTSKY, Lev S. Ape, primitive man and child. Hemel Hempstead, UK: Harvester Wheatsheaf, 1992.

MARTINS, Lígia Márcia. 0 desenvolvimento do psiquismo e a educação escolar: contribuições à luz da psicologia histórico-cultural e da pedagogia histórico-crítica. 2011. Tese (Livre docência em Psicologia da Educação) - Faculdade de Ciências, Universidade Estadual Paulista, Bauru, 2011.

SÁNCHEZ GAMBOA, Silvio. Pesquisa em educação: métodos e epistemologias. Chapecó: Argas, 2008.

SHARDAKOV, M. N. Desarrollo del pensamiento en el escolar. Habana. Editorial de Libros para la Educación, 1978.

SOARES, Carmen et al. Metodologia do ensino de educação física. 2. ed. rev. São Paulo: Cortez, 2012.

TAFFAREL, Celi Nelza Zülke. Avaliar com os pés no chão da escola: experiência da educação física. In: COSTA CARVALHO, Maria Helena. Avaliar com os pés no chão da escola: reconstruindo a prática pedagógica no ensino fundamental. Recife: Universitária da UFPE, 2000. p. $195-217$

VYGOTSKY, Lev S. A formação social da mente. São Paulo: Martins Fontes, 1984. VYGOTSKY, Lev S. Pensamento e linguagem. São Paulo: Martins Fontes, 1989. 